\title{
86038 - DOENÇAS CRÔNICAS NÃO TRANSMISSÍVEIS E LIMITAÇÕES EM IDOSOS
}

\author{
Pôster - Gerontologia
}

Valéria Baccarin laniski / IANISK, V.B / PUCRS; Luciana de Almeida da Cunha / CUNHA,L.de A. / PUCRS-RS

Introdução: As doenças crônicas não transmissíveis (DCNT) são hoje a maior epidemia em saúde pública já vista, comprometendo a expectativa e qualidade de vida dos idosos ${ }^{1}$. Objetivo: Descrever a proporção de idosos que tem diagnóstico de alguma DCNT e consequentemente limitações por esta causa. Método: Estudo descritivo de busca eletrônica de dados realizada através dos termos "doenças crônicas" e "idoso" no Sistema de Indicadores de Saúde e Acompanhamento de Políticas do Idoso (SISAP-idoso). A presença de DCNT, esta relacionada à proporção de idosos que referem ter recebido diagnóstico de DCNT e a presença de limitações, se caracteriza pela referência deles de ter alguma limitação provocada por DCNT. Os dados são oriundos da Pesquisa Nacional de Saúde, 2013. Resultados: A proporção de idosos com DCNT no país é de 76,3\%, sendo a maior proporção, $80,1 \%$, encontrada nas mulheres. Dentre as regiões, foi observada maior proporção de DCNT na região Sul (81,8\%) e também em ambos os gêneros (homens: 79,3\%; mulheres: 83,7\%). O estado de Santa Catarina apresenta a maior proporção de idosos com DCNT (83,7\%). No Brasil, a proporção de idosos com limitação por DCNT é de $45,4 \%$, sendo mais observada em mulheres, $47,6 \%$. Frente as regióes, a região Sul assume mais da metade (51\%) dos idosos com limitação por DCNT, sendo também observadas as maiores proporções com relação aos gêneros (homens: 48,4\%; mulheres: 52,9\%). O Rio Grande do Sul é o estado com mais limitações por DCNT $(53,1 \%)$. Conclusão: A região Sul é a mais afetada pelas DCNT. As mulheres apresentam mais DCNT e também limitações provocadas pelas mesmas tanto em nível de país como de regiões. 